\title{
Oxidation of tetrahydrobiopterin leads to uncoupling of endothelial cell nitric oxide synthase in hypertension
}

\author{
Ulf Landmesser, ${ }^{1}$ Sergey Dikalov, ${ }^{1}$ S. Russ Price, ${ }^{2}$ Louise McCann, ${ }^{1}$ Tohru Fukai, ${ }^{1}$ \\ Steven M. Holland, ${ }^{3}$ William E. Mitch, ${ }^{4}$ and David G. Harrison ${ }^{1}$ \\ ${ }^{1}$ Division of Cardiology, and \\ ${ }^{2}$ Division of Nephrology, Emory University School of Medicine and Atlanta Veterans Administration Hospital, \\ Atlanta, Georgia, USA \\ ${ }^{3}$ Laboratory of Host Defenses, National Institute of Allergy and Infectious Diseases, National Institutes of Health, \\ Bethesda, Maryland, USA \\ ${ }^{4}$ Department of Medicine, University of Texas, Galveston, Galveston, Texas, USA
}

\begin{abstract}
Tetrahydrobiopterin is a critical cofactor for the NO synthases, and in its absence these enzymes become "uncoupled," producing reactive oxygen species (ROSs) rather than NO. In aortas of mice with deoxycorticosterone acetate-salt (DOCA-salt) hypertension, ROS production from NO synthase is markedly increased, and tetrahydrobiopterin oxidation is evident. Using mice deficient in the NADPH oxidase subunit $\mathrm{p} 47^{p h o x}$ and mice lacking either the endothelial or neuronal NO synthase, we obtained evidence that hypertension produces a cascade involving production of ROSs from the NADPH oxidase leading to oxidation of tetrahydrobiopterin and uncoupling of endothelial NO synthase (eNOS). This decreases NO production and increases ROS production from eNOS. Treatment of mice with oral tetrahydrobiopterin reduces vascular ROS production, increases NO production as determined by electron spin resonance measurements of nitrosyl hemoglobin, and blunts the increase in blood pressure due to DOCA-salt hypertension. Endothelium-dependent vasodilation is only minimally altered in vessels of mice with DOCA-salt hypertension but seems to be mediated by hydrogen peroxide released from uncoupled eNOS, since it is inhibited by catalase. Tetrahydrobiopterin oxidation may represent an important abnormality in hypertension. Treatment strategies that increase tetrahydrobiopterin or prevent its oxidation may prove useful in preventing vascular complications of this common disease.
\end{abstract}

J. Clin. Invest. 111:1201-1209 (2003). doi:10.1172/JCI200314172.

\section{Introduction}

For several decades, it has been recognized that hypertension predisposes to atherosclerosis, although the mechanisms linking these diseases remain poorly defined. An attractive explanation for this association relates to vascular oxidant stress $(1,2)$. Accumulating evidence suggests that hypertension increases vascular production of reactive oxygen species (ROSs) (3-5). These are thought to promote atherosclerosis through a variety of mechanisms, including enhanced oxidation of lipoproteins (6), activation of proinflammatory genes (7), and stimulation of smooth-muscle growth (8), all key events in atherogenesis. A particularly

Received for publication September 7, 2001, and accepted in revised form February 18, 2003.

Address correspondence to: David G. Harrison, Division of Cardiology, Emory University School of Medicine,

1639 Pierce Drive, 319 WMB, Atlanta, Georgia 30322, USA.

Phone: (404) 727-8386; Fax: (404) 727-3585;

E-mail: dharr02@emory.edu.

Conflict of interest: The authors have declared that no conflict of interest exists.

Nonstandard abbreviations used: reactive oxygen species (ROSs); endothelial NO synthase (eNOS); neuronal NO synthase (nNOS); deoxycorticosterone (DOCA); superoxide dismutase (SOD); polyethylene glycol (PEG); L-nitroarginine methyl ester (L-NAME). important consequence of oxidant stress is loss of endothelium-derived nitric oxide, which reacts with superoxide $\left(\mathrm{O}_{2}{ }^{-}\right)$and other radicals at near diffusion-limited rates. Nitric oxide has important antiatherosclerotic properties, including inhibition of cell growth $(9,10)$, leukocyte adhesion (11), and platelet adherence and aggregation (12). These properties of $\mathrm{NO}$ are lost as a result of this reaction with $\mathrm{O}_{2}{ }^{-}$.

There has been an intense interest in the source of ROSs in blood vessels. A NADPH oxidase, similar to the neutrophil oxidase, is present in endothelial and vascular smooth-muscle cells and seems to be one source of ROSs (13). In addition, the endothelial and neuronal NO synthases (eNOS and nNOS, respectively), both cytochrome p450 reductase-like enzymes (14), can produce large amounts of ROSs when deprived of their critical cofactor tetrahydrobiopterin or their substrate L-arginine (15-21). In this state, often referred to as NOS uncoupling, electron flow through the enzyme results in reduction of molecular oxygen at the prosthetic heme site rather than formation of nitric oxide (22). If this phenomenon occurred in vivo, it could provide a mechanism for the predisposition to atherosclerosis, not only because of the increased production of ROSs but also because of the reduced formation of the protective molecule nitric oxide. In the present study, 
we provide evidence that the NO synthase cofactor tetrahydrobiopterin is oxidized in hypertensive vessels and that this leads to eNOS uncoupling, resulting in increased ROSs and reduced NO production by the enzyme. Our data suggest that the NADPH oxidase is the initial source of ROSs leading to tetrahydrobiopterin oxidation. Tetrahydrobiopterin treatment prevented eNOS uncoupling and blunted the blood pressure increase observed in deoxycorticosterone acetate-salt (DOCA-salt) hypertension.

\section{Methods}

Animals and induction of DOCA-salt bypertension. Male Sprague-Dawley rats (250-300 g; Harlan Sprague-Dawley Inc., Indianapolis, Indiana, USA) and C57BL/ 6 mice (25-35 g; Jackson Laboratories, Bar Harbor, Maine, USA) were anesthetized with intraperitoneal ketamine $(80 \mathrm{mg} / \mathrm{kg}$; Abbott Laboratories, Chicago, Illinois, USA) and xylazine $(10 \mathrm{mg} / \mathrm{kg}$; Bayer, Shawnee Mission, Kansas, USA). Using sterile techniques, the left kidney was removed through a left-flank incision. A slowrelease DOCA pellet (rats, $100 \mathrm{mg}$; mice, $50 \mathrm{mg}$ ) was inserted subcutaneously through a midscapular incision. Drinking water was replaced by $1 \%$ saline. Control animals underwent a sham operation and a placebo pellet was implanted subcutaneously. Water was given ad libitum. Measurements were performed 21 days after operation in rats and 10 days after operation in mice (unless stated otherwise). The Emory University Institutional Animal Care and Use Committee approved all animal experiments.

Mice lacking eNOS (eNOS $-/$ - mice) (23) were obtained from Jackson Laboratories. This strain has been backcrossed 10 times to the C57BL/6 strain. Mice lacking neuronal NOS ( $\mathrm{NOS}^{-/-}$mice; kindly provided by Paul L. Huang) (24) were backcrossed 10 times to the C57BL/6 strain before they were used in the present study. Mice lacking p47phox (25) were backcrossed at least seven times to the C57BL/6 background. Systolic blood pressures were measured by tail-cuff plethysmography as described previously (5). The animals were trained for the blood pressure measurements before they entered the protocol.

Measurements of vascular ROS production. Animals were sacrificed using $\mathrm{CO}_{2}$ inhalation. The aortas were rapidly removed and placed into chilled modified Krebs/HEPES buffer (composition in $\mathrm{mmol} / \mathrm{l}$ : $99.01 \mathrm{NaCl}, 4.69 \mathrm{KCl}, 2.50 \mathrm{CaCl}_{2}, 1.20 \mathrm{MgSO}_{4}, 1.03$ $\mathrm{KH}_{2} \mathrm{PO}_{4}, 25.0 \mathrm{NaHCO}_{3}, 20.0 \mathrm{Na}$-HEPES, and 5.6 glucose [pH 7.4]), cleaned of excessive adventitial tissue, with care taken not to injure the endothelium. Three different methods were used for detection of ROS production. Lucigenin-enhanced chemiluminescence was used as described before (26). Superoxide production was also measured using the superoxide dismutase-inhibitable (SOD-inhibitable) cytochrome $c$ reduction assay. For this assay, three aortic ring sections $(2 \mathrm{~mm})$ were placed in buffer containing (in mmol/l) $145 \mathrm{NaCl}, 4.86 \mathrm{KCl}, 5.7 \mathrm{NaH}_{2} \mathrm{PO}_{4}, 0.54$
$\mathrm{CaCl}_{2}, 1.22 \mathrm{MgSO}_{4}, 5.5$ glucose, 0.1 deferoxamine mesylate, and $1 \mathrm{U} / \mu \mathrm{l}$ catalase. Cytochrome $c(50 \mu \mathrm{M}$; Sigma C-4186, Sigma-Aldrich, St. Louis, Missouri, USA) was then added, and the samples were incubated at $37^{\circ} \mathrm{C}$ for 60 minutes with and without SOD $(125 \mathrm{U} / \mathrm{ml})$. Cytochrome $c$ reduction was calculated using absorbance at $550 \mathrm{~nm}$ corrected for background readings at 540 and $560 \mathrm{~nm}$. Superoxide production was quantified in picomoles per milligram of aorta from the difference between absorbance with or without SOD as previously described (27). As a third method, a fluorometric HRP-linked assay (Amplex red assay, Molecular Probes, Eugene, Oregon, USA) (28) was used to detect hydrogen peroxide production. Aortic segments $(3 \mathrm{~mm})$ were incubated for 60 minutes with Amplex red $(100 \mu \mathrm{M})$ and $\operatorname{HRP}(1 \mathrm{U} / \mathrm{ml})$ at $37^{\circ} \mathrm{C}$ in modified Krebs/HEPES buffer (described above) protected from light. Fluorescence was then measured with a fluorescent microplate reader using excitation at $530 \pm 25 \mathrm{~nm}$ and fluorescence detection at $590 \mathrm{~nm}$. Specificity of the signal for hydrogen peroxide was confirmed by treating vessels with polyethylene glycol (PEG) catalase (1000 U). Background fluorescence, determined in a control reaction without sample, was subtracted from each value. $\mathrm{H}_{2} \mathrm{O}_{2}$ production was calculated using $\mathrm{H}_{2} \mathrm{O}_{2}$ standards.

Measurements of vascular SOD activity. Aortas were homogenized in $10 \mathrm{vol}$ of $50 \mathrm{mM}$ potassium phosphate ( $\mathrm{pH}$ 7.4) containing $0.3 \mathrm{M} \mathrm{KBr}$ and a cocktail of protease inhibitors. Homogenates were sonicated and extracted at $4{ }^{\circ} \mathrm{C}$ for 30 minutes. SOD activity was assayed by examining inhibition of cytochrome $c$ reduction by xanthine/xanthine oxidase. Experiments were performed on two pooled aortas on three separate occasions.

Measurements of biopterin content in vascular tissue. Measurements of aortic biopterin content were performed using HPLC analysis and a differential oxidation method as described previously (29). The amount of $\mathrm{H}_{4} \mathrm{~B}$ was determined from the difference between total $\left(\mathrm{H}_{4} \mathrm{~B}\right.$ plus $\mathrm{H}_{2} \mathrm{~B}$ plus biopterin) and alkaline-stable oxidized $\left(\mathrm{H}_{2} \mathrm{~B}\right.$ plus biopterin) biopterin. A C-18 column $(5 \times 250 \mathrm{~mm}, 5 \mu \mathrm{m})$ was used with $5 \%$ methanol/95\% water as a solvent at a flow rate of $1.0 \mathrm{ml}$ per minute. The fluorescence detector was set at $350 \mathrm{~nm}$ for excitation and $450 \mathrm{~nm}$ for emission. Three to six mouse aortas were pooled for each measurement.

Oral treatment with tetrabydrobiopterin. Tetrahydrobiopterin was compressed into rodent chow pellets without addition of water or heating to prevent oxidation of the compound. The concentration of tetrahydrobiopterin in the pellets $(1 \mathrm{mg} / \mathrm{g})$ was calculated to provide a dose of $5 \mathrm{mg}$ per day based on an average mouse intake of 4-6 g of diet daily. Pellets were stored at $-20^{\circ} \mathrm{C}$.

Electron spin resonance analysis of nitrosyl hemoglobin levels. The three-line hyperfine spectrum of the pentacoordinate complex of NO with heme $(30,31)$ was recorded with an X-band EMX electron spin 
resonance (ESR) spectrometer (Bruker Instruments Inc., Billerica, Massachusetts, USA) using a high sensitivity SHQ microwave cavity at $77 \mathrm{~K}$. ESR spectrometer settings were as follows: microwave power, $10 \mathrm{~mW}$; modulation frequency, $100 \mathrm{kHz}$; modulation amplitude, $3 \mathrm{G}$; field center, $3300 \mathrm{G}$; sweep width, $500 \mathrm{G}$; microwave frequency, $9.396 \mathrm{GHz}$; conversion time, 655 milliseconds; time constant, 5,242 milliseconds; number of scans, 4; sweep time, 2,684 seconds. Mixed venous blood samples were obtained from the right ventricle and immediately centrifuged at 3,000 rpm. After separation from plasma, erythrocytes were resuspended in deoxygenated PBS buffer and frozen in liquid nitrogen.

Studies of vascular reactivity. Thoracic aortas were rapidly removed and cut into $3-\mathrm{mm}$ ring segments. Endothelium-dependent vasorelaxation in response to calcium ionophore A23187 and endotheliumindependent relaxation to nitroglycerin were studied as described in detail previously (32). Both responses were assessed in the absence and presence of catalase (1200 U/ml; Sigma C-100, Sigma-Aldrich) to determine the contribution of $\mathrm{H}_{2} \mathrm{O}_{2}$ to vasorelaxation (5 minutes preincubation with catalase).

Materials. DOCA and placebo pellets were purchased from Innovative Research of America (Saratoga, Florida, USA). Dihydroethidium was obtained from Molecular Probes. Tetrahydrobiopterin and tetrahydroneopterin were purchased from Schircks Laboratories (Jona, Switzerland). All other reagents were purchased from Sigma-Aldrich.

Data analysis. All data are expressed as means \pm SEM. Comparisons between groups of animals or treatments were made by one-way ANOVA, followed by either the Student-Newman-Keuls or TukeyKramer test. Values of $P<0.05$ were considered statistically significant.

\section{Results}

The endothelial NO synthase produces ROSs in hypertensive vessels. In rats with DOCA-salt hypertension (blood pressure, $189 \pm 4 \mathrm{mmHg}$ vs. $126 \pm 2 \mathrm{mmHg} ; P<0.01$ ), vascular superoxide production was increased fourfold as compared to sham-operated rats (Figure 1a). Removal of the endothelium significantly reduced superoxide levels in hypertensive rats but had no effect in normotensive rats (Figure 1a), suggesting that a significant portion of the increase in $\mathrm{O}_{2}{ }^{-}$formation in hypertensive vessels is derived from the endothelium. Because NO synthase is abundant in the endothelium, we determined if this enzyme contributed to $\mathrm{O}_{2}{ }^{-}$production in hypertension. The NO synthase inhibitor L-nitroarginine methyl ester (L-NAME) reduced $\mathrm{O}_{2}{ }^{-}-$ production in hypertensive vessels but not in control vessels, suggesting that the NO synthase is a significant source of this radical in hypertension (Figure 1a).

To confirm this finding and to determine the NOS isoform responsible for $\mathrm{O}_{2}{ }^{-}$production, we performed additional studies in genetically altered mice. In wildtype (C57BL/6) mice, we found that DOCA-salt hypertension produced an increase in vascular $\mathrm{O}_{2}{ }^{-}$production very similar to that observed in rats (Figure 1, b and c). This increase in $\mathrm{O}_{2}{ }^{-}$- production was largely blocked when NO synthase was inhibited by L-NAME (Figure 1, b and c). Neuronal NOS expression has been reported to be increased in aortas of spontaneously hypertensive rats (33) and could serve as a source of $\mathrm{O}_{2}{ }^{-}$- inhibitable by L-NAME. However, in $n \mathrm{NOS}^{-/-}$mice with DOCA-salt hypertension (blood pressure, $134 \pm 4$ $\mathrm{mmHg}$ ), vascular $\mathrm{O}_{2}{ }^{*-}$ production was increased to a similar extent as that observed in wild-type mice (Figure $1, \mathrm{~b}$ and c). As in wild-type mice, L-NAME reduced $\mathrm{O}_{2}{ }^{--}$production in $n \mathrm{NOS}^{-/-}$mice. In contrast, in $e \mathrm{NOS}^{-/-}$mice with DOCA-salt hypertension (blood pressure, $144 \pm 5 \mathrm{mmHg}$ ), there was only a modest
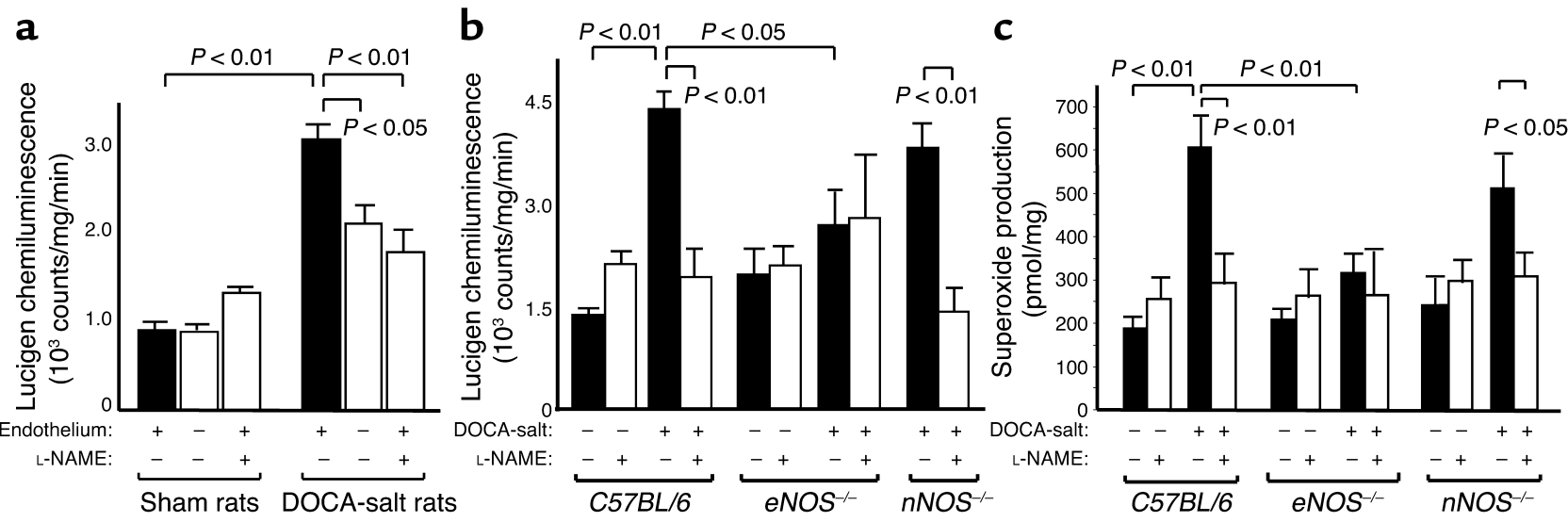

\section{Figure 1}

Role of the endothelial NO synthase as a source of ROSs in hypertensive vessels. (a) Effect of endothelial removal and NO synthase inhibition (L-NAME, $1 \mathrm{mM}$ ) on vascular superoxide $\left(\mathrm{O}_{2}{ }^{--}\right)$production estimated by lucigenin chemiluminescence in sham-operated and DOCAsalt-hypertensive rats ( $n=6-10$ per group). (b) Vascular $\mathrm{O}_{2}{ }^{--}$production estimated by lucigenin chemiluminescence in sham-operated and DOCA-salt-hypertensive wild-type (C57BL/6), eNOS ${ }^{-/-}$, and $n \mathrm{NOS}^{-/-}$knockout mice $\left(n=6-10\right.$ per group). (c) Vascular $\mathrm{O}_{2}{ }^{--}$production measured by the SOD-inhibitable cytochrome $c$ reduction assay in sham-operated and DOCA-salt-hypertensive wild-type, $e N^{-1-}$, and $n N^{-1-}$ knockout mice ( $n=5-13$ per group). 


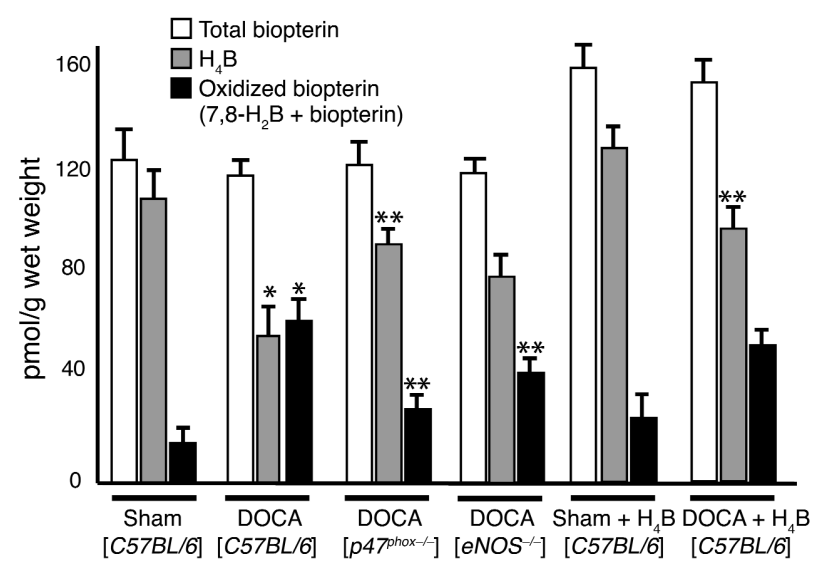

Figure 2

Tetrahydrobiopterin and oxidized biopterin content in aortas from sham-operated and DOCA-salt-hypertensive mice: effect of oral treatment with tetrahydrobiopterin, p47phox, or eNOS deficiency. Tetrahydrobiopterin $\left(\mathrm{H}_{4} \mathrm{~B}\right)$ and oxidized biopterin $\left(7,8-\mathrm{H}_{2} \mathrm{~B}\right.$ plus biopterin) were determined using HPLC analysis after differential oxidation ( $n=3-4$ per group). Three to six aortas were pooled for each measurement. ${ }^{*} P<0.05$ versus sham, ${ }^{*} P<0.05$ versus DOCA $(\mathrm{C} 57 \mathrm{BL} / 6)$.

increase in $\mathrm{O}_{2}{ }^{-}$production, and this was not altered by L-NAME (Figure 1, b and c). These findings strongly support the concept that DOCA-salt hypertension is associated with an increase in $\mathrm{O}_{2}{ }^{-}$production from eNOS and that nNOS does not significantly contribute to this phenomenon.

One explanation for an increase in $\mathrm{O}_{2}{ }^{-}$production in hypertensive vessels might relate to a decrease in the activity of SOD in these vessels. Total SOD activity, however, was identical in vessels of sham-operated and hypertensive mice, averaging $7.6 \pm 1.0 \mathrm{U} / \mathrm{mg}$ of protein and $7.4 \pm 1.1 \mathrm{U} / \mathrm{mg}$ of protein, respectively $(n=3$ for each; difference not significant).

Oxidation of tetrahydrobiopterin in hypertension. Tetrahydrobiopterin plays a crucial role as a cofactor for all $\mathrm{NO}$ synthases $(22,34)$. In its absence, purified eNOS produces ROSs rather than NO (15-17). Thus, one mechanism whereby eNOS could become uncoupled in vivo may be due to diminished levels of tetrahydrobiopterin. In preliminary experiments, we found that endothelial removal before homogenization of vessels reduced total biopterin levels by $60-70 \%$, suggesting that the major site of tetrahydrobiopterin synthesis in the vessel wall is the endothelium. Total biopterin content in aortas from control and DOCA-salt-hypertensive mice was similar (Figure 2). In vessels from mice with DOCA-salt

\section{Figure 3}

Effect of NADPH oxidase deficiency $\left(p 47^{\text {phox- }--}\right)$ and treatment with tetrahydrobiopterin $\left(\mathrm{H}_{4} \mathrm{~B}\right)$ on vascular $\mathrm{O}_{2}{ }^{*-}$ production in DOCAsalt hypertension. (a) Vascular $\mathrm{O}_{2}{ }^{--}$production estimated by lucigenin chemiluminescence in sham-operated and DOCAsalt-hypertensive mice ( $n=6-10$ per group). (b) Vascular $\mathrm{O}_{2}{ }^{-}$ production measured by the SOD-inhibitable cytochrome $c$ reduction assay ( $n=5-13$ per group). hypertension, however, the tetrahydrobiopterin content was substantially reduced, and the content of oxidized forms of tetrahydrobiopterin (7,8-dihydrobiopterin and biopterin) was correspondingly increased.

These data suggest that oxidation of tetrahydrobiopterin leads to tetrahydrobiopterin deficiency in hypertension (Figure 2) and raise the question of what may be the initial source of ROSs in hypertension leading to tetrahydrobiopterin oxidation. Previous studies have shown that peroxynitrite, the reaction product of $\mathrm{NO}$ and $\mathrm{O}_{2}{ }^{--}$, and a variety of other oxidants that could potentially be derived from $\mathrm{O}_{2}{ }^{--}$can oxidize tetrahydrobiopterin $(26,35,36)$. We hypothesized that the vascular NADPH oxidase might be an initial source of $\mathrm{O}_{2}{ }^{-}$that leads to formation of peroxynitrite and other oxidants, since this enzyme system represents an important source of $\mathrm{O}_{2}{ }^{--}$in endothelial cells $(37,38)$. We therefore studied mice lacking p47phox, a critical component of the vascular NADPH oxidase $(39,40)$. In contrast to the findings in wild-type mice with DOCA-salt hypertension, levels of tetrahydrobiopterin and oxidized biopterin were similar to those observed in sham-operated mice (Figure 2). In addition, there was no increase in vascular $\mathrm{O}_{2}{ }^{-}$production in DOCA-salt-hypertensive $\mathrm{p} 47^{\text {phox }}$ deficient mice (Figure 3). In contrast to DOCAsalt-treated wild-type mice, exposure of aortas from p47phox-deficient mice with DOCA-salt hypertension to L-NAME did not reduce $\mathrm{O}_{2}{ }^{--}$production (Figure 3 ).
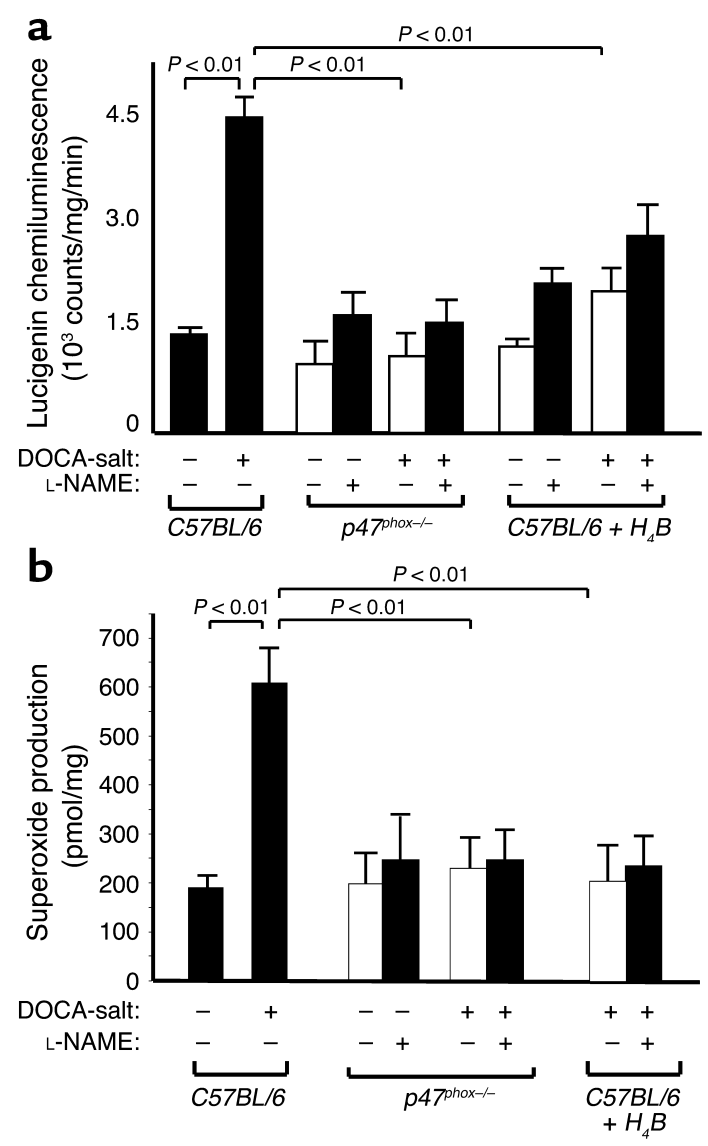

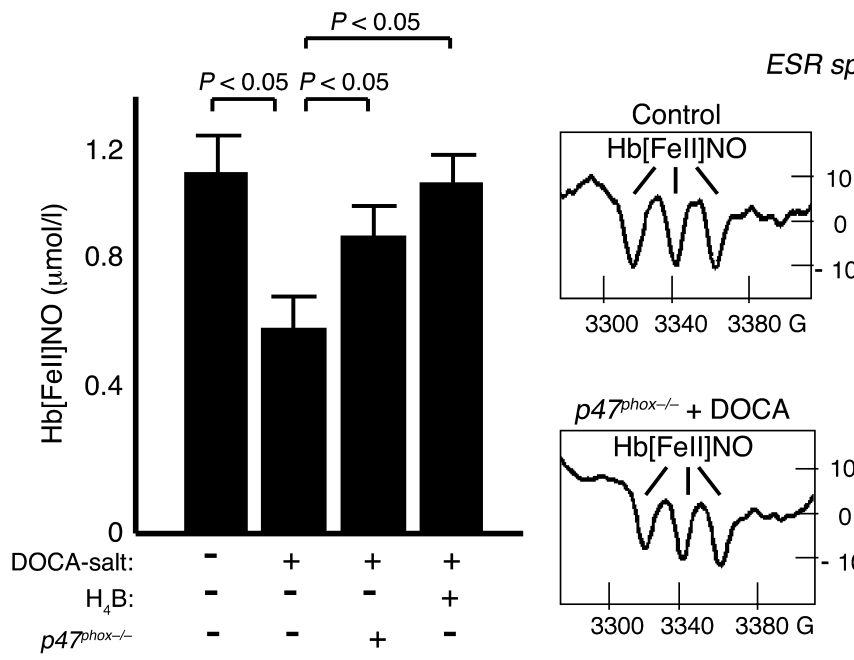

ESR spectra

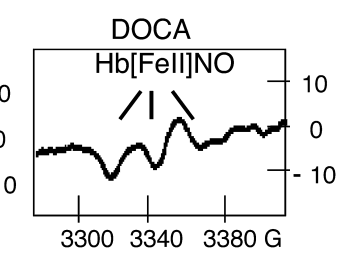

Figure 4

Effect of NADPH oxidase deficiency (p47phox-l-) and tetrahydrobiopterin $\left(\mathrm{H}_{4} \mathrm{~B}\right)$ treatment on $\mathrm{NO}$ production. $\mathrm{NO}$ production was analyzed by ESR measurements of nitrosyl hemoglobin levels $(n=5)$.
These findings indicate that in the absence of a functioning NADPH oxidase, eNOS is not uncoupled by DOCA-salt hypertension. A significant role of reactive nitrogen species derived from eNOS in tetrahydrobiopterin oxidation is suggested by the fact that in DOCA-salt-treated eNOS-deficient mice, there was less tetrahydrobiopterin oxidation than in hypertensive wild-type mice (Figure 2).

Effect of oral treatment with tetrahydrobiopterin in hypertension. The above studies demonstrated that eNOS is uncoupled in hypertension and suggest that tetrahydrobiopterin oxidation may underlie this phenomenon.
To further evaluate this concept, we treated mice with oral tetrahydrobiopterin and measured vascular $\mathrm{O}_{2}{ }^{-}$ production. Treatment with oral tetrahydrobiopterin (5 mg per day), beginning one day after surgery, increased tetrahydrobiopterin by about twofold in hypertensive mice and to a lesser extent in control mice but did not change the levels of oxidized biopterin in either of these groups (Figure 2). Tetrahydrobiopterin treatment resulted in a substantial reduction of $\mathrm{O}_{2}{ }^{-}$production in mice with DOCA-salt hypertension (Figure 3 ). Of note, L-NAME no longer caused a decrease in $\mathrm{O}_{2}{ }^{-}$production in aortas of
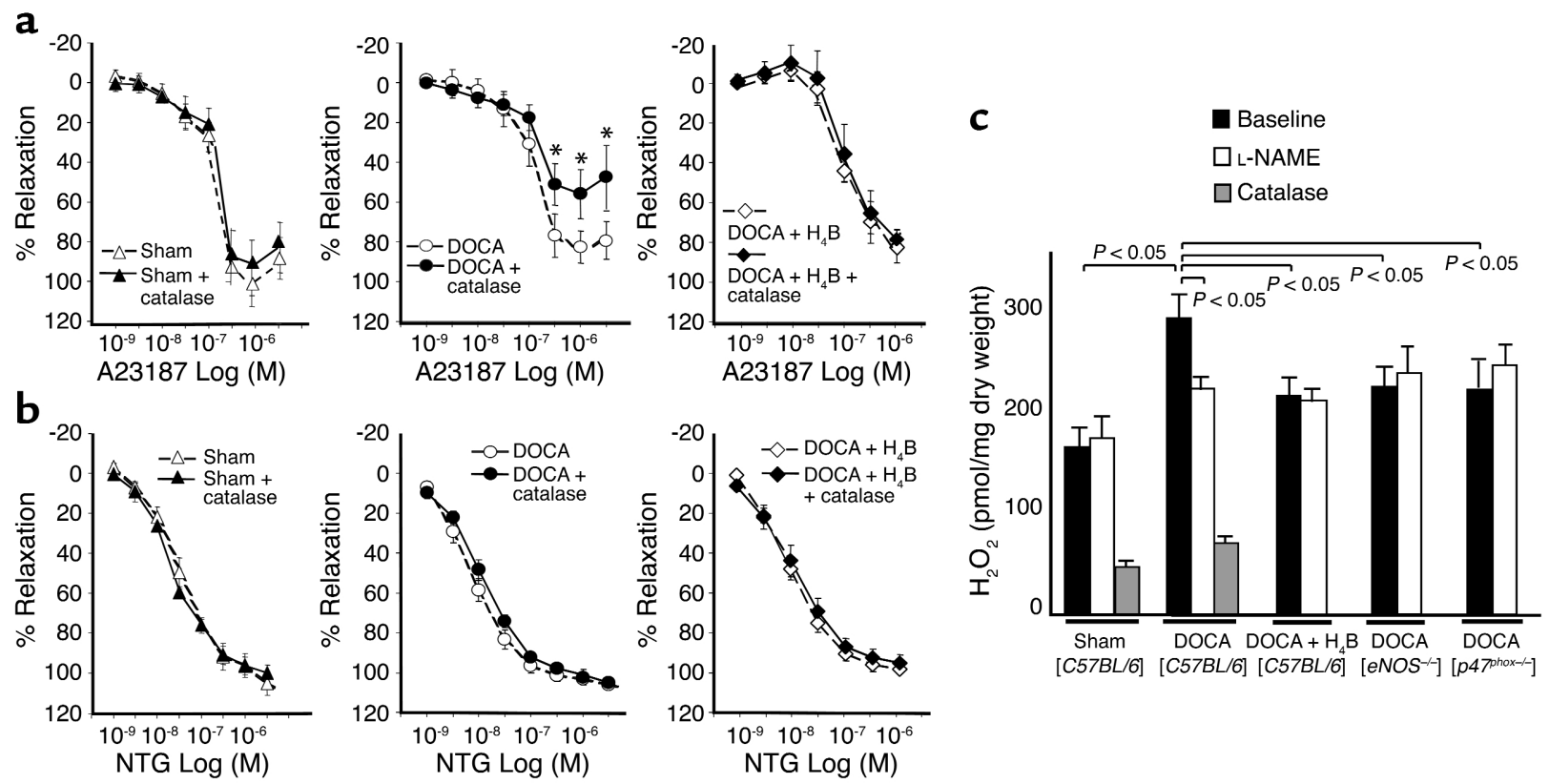

Figure 5

Endothelium-dependent vascular relaxation in DOCA-salt hypertension: role of hydrogen peroxide. Effect of catalase (1200 U/ml) on endothelium-dependent vasorelaxations to calcium ionophore $\mathrm{A} 23187$ (a) and endothelium-independent vasorelaxations to nitroglycerin (b) in aortas from sham-operated, DOCA-salt-hypertensive mice and hypertensive mice treated with $\mathrm{H}_{4} \mathrm{~B}\left(n=6-10,{ }^{*} P<0.05\right)$. (c) $\mathrm{H}_{2} \mathrm{O}_{2}$ production in aortas from sham-operated, DOCA-salt-hypertensive mice (with and without oral $\mathrm{H}_{4} \mathrm{~B}$ treatment) and DOCA-salt-treated eNOS ${ }^{-/-}$and $\mathrm{p} 47_{\text {phox- } /-}$ mice. $\mathrm{H}_{2} \mathrm{O}_{2}$ production was determined by the fluorometric Amplex red assay in the presence of $\mathrm{A} 23187$ (10-6 $\mathrm{M}$ ). The effect of NO synthase inhibition ( $1 \mathrm{mM}$ L-NAME) and PEG catalase (1000 U) was studied $(n=3-6)$. 
Table 1

Effect of oral $\mathrm{H}_{4} \mathrm{~B}$ treatment or $\mathrm{NADPH}$ oxidase deficiency on systolic blood pressure $(\mathrm{mmHg})$

\begin{tabular}{|c|c|c|c|c|c|}
\hline & $\begin{array}{l}\text { Sham } \\
n=8\end{array}$ & $\begin{array}{c}\text { Sham plus } \mathrm{H}_{4} \mathrm{~B} \\
n=5\end{array}$ & $\begin{array}{l}\text { DOCA } \\
n=8\end{array}$ & $\begin{array}{c}\text { DOCA plus } \mathrm{H}_{4} \mathrm{~B} \\
n=6\end{array}$ & $\begin{array}{c}\text { DOCA plus } p 47_{\text {phox- }-1-} \\
\qquad n=5\end{array}$ \\
\hline Day 10 & $104 \pm 2$ & $103 \pm 2$ & $136 \pm 3^{A}$ & $132 \pm 3$ & $130 \pm 3$ \\
\hline Day 20 & $105 \pm 2$ & $103 \pm 3$ & $141 \pm 3^{A}$ & $133 \pm 2^{B}$ & $132 \pm 3^{B}$ \\
\hline Day 30 & $104 \pm 2$ & $102 \pm 3$ & $146 \pm 3^{\mathrm{A}}$ & $132 \pm 3^{B}$ & $131 \pm 4^{\mathrm{B}}$ \\
\hline
\end{tabular}

hypertensive mice treated with tetrahydrobiopterin (Figure 3, a and b). In vessels of sham-operated mice there was no effect of treatment with tetrahydrobiopterin on $\mathrm{O}_{2}{ }^{--}$production (Figure 3).

Reduced pteridines such as tetrahydrobiopterin may exert antioxidant effects in vitro that could contribute to the effect on $\mathrm{O}_{2}{ }^{-}$production we observed in hypertensive mice fed $\mathrm{H}_{4} \mathrm{~B}$ (41). Treatment with oral tetrahydroneopterin $\left(\mathrm{H}_{4} \mathrm{~N}, 5 \mathrm{mg}\right.$ per day), which has antioxidant properties similar to those of $\mathrm{H}_{4} \mathrm{~B}$ (42) but poorly sustains eNOS catalysis, failed to reduce vascular $\mathrm{O}_{2}{ }^{-}$production in mice with DOCAsalt hypertension $\left(\mathrm{O}_{2}{ }^{-}\right.$production, $5.87 \pm 2.1 \times 10^{3}$ counts/mg per minute; $n=4)$. This indicates that tetrahydrobiopterin is not simply acting as an antioxidant in hypertension.

Because uncoupling of eNOS not only causes the enzyme to produce $\mathrm{O}_{2}{ }^{-}$but also decreases $\mathrm{NO}$ formation, we studied the effect of oral tetrahydrobiopterin treatment on NO formation, reflected by nitrosyl hemoglobin levels in the blood. In hypertensive mice, nitrosyl hemoglobin levels, as determined by ESR measurements, were significantly reduced as compared with those in sham-operated mice (Figure 4). This abnormality was corrected by oral tetrahydrobiopterin treatment (Figure 4). In keeping with the concept that the NADPH oxidase is at least in part responsible for oxidation of tetrahydrobiopterin and reducing NO production in hypertension, we found that nitrosyl hemoglobin levels in hypertensive p47phox-deficient mice were similar to those observed in controls (Figure 4).

Endothelium-dependent vascular relaxation in DOCA-salt hypertension: role of bydrogen peroxide. It has recently been demonstrated that depletion of tetrahydrobiopterin in intact vessels has minimal effect on endothelium-dependent vasodilation, but that these responses are markedly inhibited by the addition of catalase, suggesting that they are mediated by $\mathrm{H}_{2} \mathrm{O}_{2}$ $(43,44)$. We therefore examined the effect of catalase on endothelium-dependent vasodilation in aortas from sham-operated and DOCA-salt-hypertensive mice and in tetrahydrobiopterin-treated mice with DOCA-salt hypertension. Relaxations evoked by the calcium ionophore A23187 were only minimally reduced in vessels from hypertensive mice as compared with sham-operated mice (Figure 5a). Catalase had no effect on relaxations to A23187 in sham-operated vessels; however, in vessels from hypertensive mice, catalase inhibited these responses by approximately $50 \%$ (Figure 5a). This effect of catalase was no longer observed in hypertensive mice treated with tetrahydrobiopterin. Endothelium-independent relaxation to nitroglycerin was similar between hypertensive and sham-operated mice and was not affected by catalase (Figure $5 b$ ). The vasorelaxation studies were not performed in eNOS-deficient mice, since we have previously shown that aortas from these mice lack relaxation in response to A23187 (32).

In additional experiments, we examined the ability of A23187 to stimulate release of $\mathrm{H}_{2} \mathrm{O}_{2}$ from vascular segments using the Amplex red assay. As shown in Figure $5 c$, the production of $\mathrm{H}_{2} \mathrm{O}_{2}$ in response to $\mathrm{A} 23187$ was increased by approximately twofold in vessels from mice with DOCA-salt hypertension. This increased response was not observed if vessels were treated with L-NAME, if the animals were treated with oral tetrahydrobiopterin, or when either eNOS- or p47phox-deficient mice were studied (Figure 5c). Endothelial removal decreased vascular $\mathrm{H}_{2} \mathrm{O}_{2}$ production in DOCA-salt-hypertensive mice (from $283 \pm 21$ pmol $\mathrm{H}_{2} \mathrm{O}_{2}$ per milligram to $223 \pm 22$ pmol $_{2} \mathrm{O}_{2}$ per milligram, $P<0.05)$ but had no significant effect in sham mice $\left(133 \pm 16 \mathrm{pmol} \mathrm{H}_{2} \mathrm{O}_{2}\right.$ per milligram vs. $167 \pm 18 \mathrm{pmol} \mathrm{H}_{2} \mathrm{O}_{2}$ per milligram). The specificity of the Amplex red signal for $\mathrm{H}_{2} \mathrm{O}_{2}$ was confirmed using PEG catalase (1000 U) (Figure 5c).

Taken together, these data suggest that endotheliumdependent vasodilation is in part mediated by $\mathrm{H}_{2} \mathrm{O}_{2}$ in the setting of DOCA-salt hypertension. Our studies of $\mathrm{H}_{2} \mathrm{O}_{2}$ production strongly suggest that a major source of $\mathrm{H}_{2} \mathrm{O}_{2}$ in this situation is uncoupled eNOS.

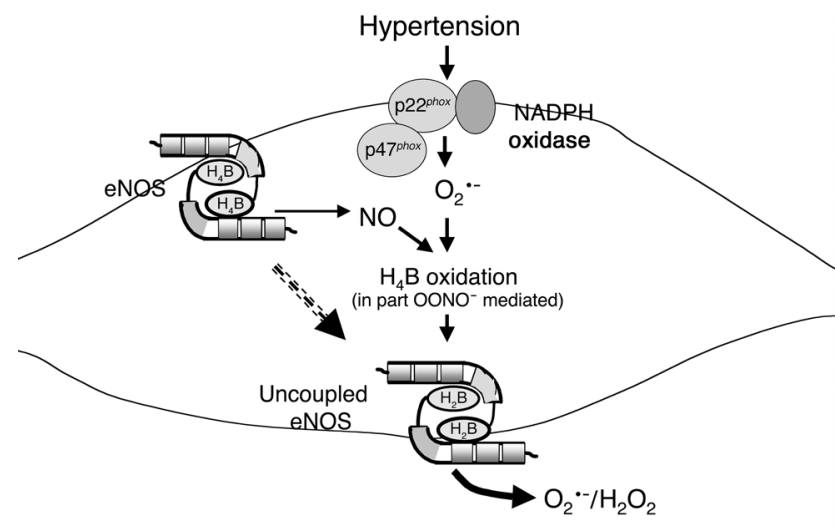

\section{Figure 6}

Proposed concept of eNOS uncoupling in hypertension. Hypertension stimulates $\mathrm{O}_{2}{ }^{--}$formation from the vascular NADPH oxidase. This results in oxidation of the eNOS cofactor tetrahydrobiopterin $\left(\mathrm{H}_{4} \mathrm{~B}\right)$. Our data suggest that peroxynitrite $\left(\mathrm{ONOO}^{-}\right)$or oxidants derived from peroxynitrite contribute to tetrahydrobiopterin oxidation. Cofactor-deficient eNOS or eNOS with oxidized forms of $\mathrm{H}_{4} \mathrm{~B}$ produces large amounts of $\mathrm{O}_{2}{ }^{\bullet-}$ upon stimulation of the enzyme. 
Effect of tetrabydrobiopterin treatment and NADPH oxidase deficiency on the progression of bypertension. The effect of tetrahydrobiopterin treatment and NADPH oxidase deficiency on blood pressure was evaluated at 10, 20, and 30 days after DOCA-salt treatment. At the early time point (10 days), there was a trend toward a lower blood pressure in tetrahydrobiopterin- and NADPH oxidase-deficient DOCA-salt mice (Table 1). In animals with untreated DOCA-salt hypertension, blood pressure continued to increase for the ensuing 20 days. In mice treated with tetrahydrobiopterin and mice lacking $\mathrm{p} 47$ phox , blood pressures remained unchanged after the initial increase at 10 days and were statistically lower than those in untreated DOCA-salt mice (Table 1).

\section{Discussion}

The results of the present study suggest a cascade of events leading to eNOS uncoupling in hypertension. As illustrated in Figure 6, our data indicate that the $\mathrm{NADPH}$ oxidase is critically important in producing ROSs that ultimately oxidize tetrahydrobiopterin in blood vessels of hypertensive animals. Our findings further suggest that this loss of tetrahydrobiopterin alters the function of eNOS, resulting in diminished $\mathrm{NO}$ production and increased production of ROSs from the enzyme. Oral treatment with tetrahydrobiopterin or NADPH oxidase deficiency blunts the increase in blood pressure caused by DOCA-salt hypertension in mice, suggesting that eNOS uncoupling contributes to the progression of hypertension.

Accumulating evidence suggests that the NADPH oxidase is a major source of ROSs in the vessel wall (13). Our present studies suggest that there is an important interaction between this oxidase and eNOS, whereby increased production of ROSs by the former impairs NO production and stimulates production of ROSs by the latter. Thus, the NADPH oxidase can contribute to oxidant stress not only by producing $\mathrm{O}_{2}{ }^{-}$but also by initiating tetrahydrobiopterin oxidation, leading to eNOS uncoupling. The combination of reduced NO and increased ROS production may not only contribute to the maintenance and progression of hypertension but could also have proatherogenic effects. Nitric oxide inhibits vascular smooth-muscle cell proliferation $(9,10)$, whereas ROSs stimulate smooth-muscle cell growth $(8,45)$. This may contribute to the vascular smooth-muscle growth and hypertrophy observed in hypertensive vessels. Likewise, NO has potent antiatherogenic effects, such as inhibition of leukocyte adhesion $(11,46)$ and platelet aggregation (12), whereas ROSs seem to activate these processes $(2,7,47)$. Given these considerations, oxidation of tetrahydrobiopterin and uncoupling of eNOS may have important effects on vascular homeostasis in hypertension.

In both endothelial and vascular smooth-muscle cells, mechanical stretch has been shown to activate the NADPH oxidase (48-50), and it is possible that stretch of vascular cells caused by hypertension may lead to increased $\mathrm{O}_{2}{ }^{--}$production by this enzyme complex. In addition, angiotensin II is a potent stimulus of the NADPH oxidase (51). Although DOCA-salt hypertension is considered a low-renin state, Bardy et al. have recently shown that vascular stretch can activate local angiotensin II production (52). Schiffrin et al. have reported that angiotensin receptors are upregulated in aortas from rats with DOCA-salt hypertension (53), and others have shown that vascular angiotensinogen expression is increased in DOCA-salt hypertension (54). Thus, activation of the local renin-angiotensin system may contribute to increases in NADPH oxidase activity in this model. It is also possible that there is a contribution of infiltrating leukocytes to increased NADPH oxidase activity in hypertensive vessels.

Recently, we have shown that peroxynitrite is much more potent than $\mathrm{O}_{2}{ }^{-}$in oxidizing tetrahydrobiopterin (26). It is therefore likely that $\mathrm{O}_{2}{ }^{-}$made by the NADPH oxidase is not the relevant oxidant, but that other oxidants such as peroxynitrite are involved in tetrahydrobiopterin oxidation in hypertension. It is improbable that all eNOS is uncoupled in hypertension, but it is likely that some of the enzyme produces $\mathrm{NO}$ and some produces ROSs. This may lead to ongoing production of peroxynitrite in the endothelium, which then continues to oxidize tetrahydrobiopterin and sustains uncoupling of the enzyme. This concept is supported by our observation that in both $\mathrm{p} 47^{\text {phox }}$-deficient and eNOS-deficient hypertensive mice, there was less tetrahydrobiopterin than in wild-type mice with hypertension. These reactions may represent a self-perpetuating source of ROSs within the endothelium in hypertension. In addition, other derived oxidants may also contribute to tetrahydrobiopterin oxidation. Rate constants for reactions of radicals such as GSSG', GS', and $\mathrm{CO}^{\circ}{ }^{-}$with tetrahydrobiopterin have recently been shown to be very rapid (36).

Nitrosyl hemoglobin levels, as detected by ESR spectroscopy, were reduced in hypertensive animals in the present study and could be normalized by both tetrahydrobiopterin treatment and p47phox deficiency, suggesting that tetrahydrobiopterin oxidation is associated with impaired NO production in hypertension.

In the present studies, three separate methods were used to determine ROS production in hypertensive vessels. All approaches indicated that vascular ROS production was reduced by $\mathrm{p} 47^{\text {phox }}$ and eNOS deficiency in DOCA-salt hypertension, suggesting that the NADPH oxidase and uncoupled eNOS represent important sources of increased vascular ROS production in hypertensive vessels. There was still measurable ROS production in $\mathrm{p} 47^{\text {phox }}$ - and eNOS-deficient mice, suggesting that other sources of ROSs in endothelial and vascular smooth-muscle cells (i.e., xanthine oxidase, cytochrome $\mathrm{p} 450$, and mitochondria) may contribute to basal ROS formation. These observations are compatible with recent findings of Li et al. (55) in cultured endothelial cells from p47phoxdeficient mice, who found no reduction in basal ROS 
production but a reduced response to TNF- $\alpha$ and

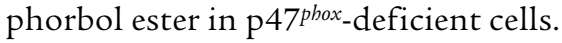

Our studies of endothelium-dependent vascular relaxation support the concept that uncoupled eNOS can serve as a source of increased $\mathrm{H}_{2} \mathrm{O}_{2}$ production in hypertension. Cosentino et al. demonstrated that inhibition of tetrahydrobiopterin synthesis leads to $\mathrm{H}_{2} \mathrm{O}_{2}$-mediated endothelium-dependent vasodilation $(43,44)$, a phenomenon that is compatible with the observations of the present study in hypertensive mice that become tetrahydrobiopterin deficient due to increased oxidation of this eNOS cofactor. There are at least two known mechanisms whereby $\mathrm{H}_{2} \mathrm{O}_{2}$ may cause vasodilation. One involves activation of catalase to compound I, which then forms a complex with guanylate cyclase to stimulate production of cGMP (56). In addition, it has been reported that $\mathrm{H}_{2} \mathrm{O}_{2}$ can act as an endothelium-dependent hyperpolarizing factor (57). Increasing evidence has emphasized an important role of $\mathrm{H}_{2} \mathrm{O}_{2}$ in vascular disease. In contrast to other short-lived oxidants, $\mathrm{H}_{2} \mathrm{O}_{2}$ is relatively stable and can diffuse from one cell to the next. $\mathrm{H}_{2} \mathrm{O}_{2}$ has several recently identified intracellular signaling targets (58) and plays a crucial role in vascular smoothmuscle cell growth and hypertrophy $(59,60)$.

This dual role of $\mathrm{H}_{2} \mathrm{O}_{2}$ may explain the more pronounced effect of tetrahydrobiopterin treatment or p47phox deficiency on blood pressure at later time points observed in this study. Although the vasodilator effects of $\mathrm{H}_{2} \mathrm{O}_{2}$ may maintain vasomotion over the short-term, production of $\mathrm{H}_{2} \mathrm{O}_{2}$ over the long term may contribute to vascular smooth-muscle hypertrophy and remodeling events leading to the progression of hypertension at latter time points. The reduction of $\mathrm{H}_{2} \mathrm{O}_{2}$ by tetrahydrobiopterin treatment or NADPH oxidase deficiency would reduce this progression of hypertension. As suggested by Huang et al., the initial increase in blood pressure in DOCA-salt hypertension is largely due to salt and volume expansion (61), and would likely be prevented by tetrahydrobiopterin treatment or alteration of NADPH oxidase activity.

Of note, it has recently been shown that ascorbate increases tetrahydrobiopterin levels in cultured endothelial cells by preventing its oxidation rather than by increasing its synthesis (62). Thus, preservation of tetrahydrobiopterin may explain the observed effect of long-term ascorbate treatment on blood pressure in patients with hypertension (63).

On the basis of our current findings, we propose that tetrahydrobiopterin oxidation represents an important abnormality of vascular function in hypertension. Treatment with tetrahydrobiopterin or prevention of its oxidation may prove useful in preventing the vascular complications of this common disease.

\section{Acknowledgments}

We gratefully acknowledge excellent technical support by Graciela Gamez and Bin Zheng. This work was supported by NIH grants HL390006 (to D.G. Harrison),
HL59248 (to D.G. Harrison), DK50740 (to S.R. Price), and DK37175 (to W.E. Mitch) and NIH Program Project Grant HL58000 (to D.G. Harrison,) and a Department of Veterans Affairs merit grant (to D.G. Harrison). U. Landmesser was supported by a grant from the German Cardiac Society and the Feodor Lynen grant of the Alexander von Humboldt Foundation.

1. Alexander, R.W. 1995. Theodore Cooper Memorial Lecture. Hypertension and the pathogenesis of atherosclerosis. Oxidative stress and the mediation of arterial inflammatory response: a new perspective. Hypertension. 25:155-161.

2. Cai, H., and Harrison, D.G. 2000. Endothelial dysfunction in cardiovascular diseases: the role of oxidant stress. Circ. Res. 87:840-844.

3. Nakazono, K., et al. 1991. Does superoxide underlie the pathogenesis of hypertension? Proc. Natl. Acad. Sci. U. S. A. 88:10045-10048.

4. Laursen, J.B., et al. 1997. Role of superoxide in angiotensin II-induced but not catecholamine-induced hypertension. Circulation. 95:588-593.

5. Somers, M.J., et al. 2000. Vascular superoxide production and vasomotor function in hypertension induced by deoxycorticosterone acetatesalt. Circulation. 101:1722-1728.

6. Steinberg, D., and Lewis, A. 1997. Conner Memorial Lecture. Oxidative modification of LDL and atherogenesis. Circulation. 95:1062-1071.

7. Marui, N., et al. 1993. Vascular cell adhesion molecule-1 (VCAM-1) gene transcription and expression are regulated through an antioxidant-sensitive mechanism in human vascular endothelial cells. J. Clin. Invest. 92:1866-1874.

8. Griendling, K.K., and Ushio-Fukai, M. 1998. Redox control of vascular smooth muscle proliferation. J. Lab. Clin. Med. 132:9-15.

9. Garg, U.C., and Hassid, A. 1989. Nitric oxide-generating vasodilators and 8-bromo-cyclic guanosine monophosphate inhibit mitogenesis and proliferation of cultured rat vascular smooth muscle cells. J. Clin. Invest. 83:1774-1777.

10. Tanner, F.C., et al. 2000. Nitric oxide modulates expression of cell cycle regulatory proteins: a cytostatic strategy for inhibition of human vascular smooth muscle cell proliferation. Circulation. 101:1982-1989.

11. Kubes, P., Suzuki, M., and Granger, D.N. 1991. Nitric oxide: an endogenous modulator of leukocyte adhesion. Proc. Natl. Acad. Sci. U. S. A. 88:4651-4655.

12. Cooke, J.P., and Dzau, V.J. 1997. Nitric oxide synthase: role in the genesis of vascular disease. Annu. Rev. Med. 48:489-509.

13. Griendling, K.K., Sorescu, D., and Ushio-Fukai, M. 2000. NAD(P)H oxidase: role in cardiovascular biology and disease. Circ. Res. 86:494-501.

14. Bredt, D.S., et al. 1991. Cloned and expressed nitric oxide synthase structurally resembles cytochrome P-450 reductase. Nature. 351:714-718.

15. Wever, R.M., et al. 1997. Tetrahydrobiopterin regulates superoxide and nitric oxide generation by recombinant endothelial nitric oxide synthase. Biochem. Biophys. Res. Commun. 237:340-344.

16. Xia, Y., et al. 1998. Superoxide generation from endothelial nitric-oxide synthase. $\mathrm{A} \mathrm{Ca}^{2+} /$ calmodulin-dependent and tetrahydrobiopterin regulatory process. J. Biol. Chem. 273:25804-25808.

17. Vasquez-Vivar, J., et al. 1998. Superoxide generation by endothelial nitric oxide synthase: the influence of cofactors. Proc. Natl. Acad. Sci. U. S. A. 95:9220-9225.

18. Xia, Y., et al. 1996. Nitric oxide synthase generates superoxide and nitric oxide in arginine-depleted cells leading to peroxynitrite-mediated cellular injury. Proc. Natl. Acad. Sci. U. S. A. 93:6770-6774.

19. Pou, S., et al. 1999. Mechanism of superoxide generation by neuronal nitric-oxide synthase. J. Biol. Chem. 274:9573-9580.

20. Heinzel, B., et al. 1992. $\mathrm{Ca}^{2+} /$ calmodulin-dependent formation of hydrogen peroxide by brain nitric oxide synthase. Biochem. J. 281:627-630.

21. Cosentino, F., and Luscher, T.F. 1999. Tetrahydrobiopterin and endothelial nitric oxide synthase activity. Cardiovasc. Res. 43:274-278.

22. Stuehr, D., Pou, S., and Rosen, G.M. 2001. Oxygen reduction by nitricoxide synthases. J. Biol. Chem. 276:14533-14536.

23. Shesely, E.G., et al. 1996. Elevated blood pressures in mice lacking endothelial nitric oxide synthase. Proc. Natl. Acad. Sci. U. S. A. 93:13176-13181.

24. Huang, P.L., et al. 1993. Targeted disruption of the neuronal nitric oxide synthase gene. Cell. 75:1273-1286.

25. Jackson, S.H., Gallin, J.I., and Holland, S.M. 1995. The p47phox mouse knock-out model of chronic granulomatous disease. J. Exp. Med. 182:751-758

26. Laursen, J.B., et al. 2001. Endothelial regulation of vasomotion in apoEdeficient mice: implications for interactions between peroxynitrite and tetrahydrobiopterin. Circulation. 103:1282-1288.

27. Kolbeck, R.C., She, Z.W., Callahan, L.A., and Nosek, T.M. 1997. Increased superoxide production during fatigue in the perfused rat diaphragm. Am. J. Respir. Crit. Care Med. 56:140-145. 
28. Zhou, M., et al. 1997. A stable nonfluorescent derivative of resorufin for the fluorometric determination of trace hydrogen peroxide: applications in detecting the activity of phagocyte NADPH oxidase and other oxidases. Anal. Biochem. 253:162-168.

29. Fukushima, T., and Nixon, J.C. 1980. Analysis of reduced forms of biopterin in biological tissues and fluids. Anal. Biochem. 102:176-188.

30. Kosaka, H., and Shiga, T. 1996. Detection of nitric oxide by electron spin resonance using hemoglobin. In Methods in nitric oxide research. M. Feelisch and J.S. Stamler, editors. John Wiley and Sons. Chichester, United Kingdom. 373-381.

31. Henry, Y.A. 1997. EPR characterization of nitric oxide binding to hemoglobin. In Nitric oxide research from chemistry to biology: EPR spectroscopy of nitrosylated compounds. Y.A. Henry, A. Guissani, and B. Ducastel, editors. Chapman and Hall. New York, New York, USA. 60-86.

32. Kojda, G., et al. 1999. Protein expression, vascular reactivity and soluble guanylate cyclase activity in mice lacking the endothelial cell nitric oxide synthase: contributions of NOS isoforms to blood pressure and heart rate control. Cardiovasc. Res. 42:206-213.

33. Boulanger, C.M., et al. 1998. Neuronal nitric oxide synthase is expressed in rat vascular smooth muscle cells: activation by angiotensin II in hypertension. Circ. Res. 83:1271-1278.

34. Stuehr, D.J. 1997. Structure-function aspects in the nitric oxide synthases. Annu. Rev. Pharmacol. Toxicol. 37:339-359.

35. Milstien, S., and Katusic, Z. 1999. Oxidation of tetrahydrobiopterin by peroxynitrite: implications for vascular endothelial function. Biochem. Biophys. Res. Commun. 263:681-684.

36. Patel, K.B., et al. 2002. Oxidation of tetrahydrobiopterin by biological radicals and scavenging of the trihydrobiopterin radical by ascorbate. Free Radic. Biol. Med. 32:203-211.

37. Somers, M.J., Burchfield, J.S., and Harrison, D.G. 2000. Evidence for a $\mathrm{NADH} / \mathrm{NADPH}$ oxidase in human umbilical vein endothelial cells using electron spin resonance. Antioxid. Redox Signal. 2:779-787.

38. Bayraktutan, U., Blayney, L., and Shah, A.M. 2000. Molecular characterization and localization of the $\mathrm{NAD}(\mathrm{P}) \mathrm{H}$ oxidase components gp91phox and p22-phox in endothelial cells. Arterioscler. Thromb. Vasc. Biol. 20:1903-1911.

39. Lavigne, M.C., et al. 2001. Genetic demonstration of p47phox-dependent superoxide anion production in murine vascular smooth muscle cells. Circulation. 104:79-84

40. Patterson, C., et al. 1999. Stimulation of a vascular smooth muscle cell $\mathrm{NAD}(\mathrm{P}) \mathrm{H}$ oxidase by thrombin. Evidence that $\mathrm{p} 47$ (phox) may participate in forming this oxidase in vitro and in vivo. J. Biol. Chem. 274:19814-19822.

41. Shen, R.S. 1994. Inhibition of luminol-enhanced chemiluminescence by reduced pterins. Arch. Biochem. Biophys. 310:60-63.

42. Heitzer, T., et al. 2000. Tetrahydrobiopterin improves endotheliumdependent vasodilation in chronic smokers: evidence for a dysfunctional nitric oxide synthase. Circ. Res. 86:E36-E41.

43. Cosentino, F., and Katusic, Z.S. 1995. Tetrahydrobiopterin and dysfunction of endothelial nitric oxide synthase in coronary arteries. Circu lation. 91:139-144.

44. Cosentino, F., et al. 2001. Reactive oxygen species mediate endotheliumdependent relaxations in tetrahydrobiopterin-deficient mice. Arterioscler. Thromb. Vasc. Biol. 21:496-502.

45. Irani, K. 2000. Oxidant signaling in vascular cell growth, death, and survival: a review of the roles of reactive oxygen species in smooth muscle and endothelial cell mitogenic and apoptotic signaling. Circ. Res. 87:179-183.

46. Tsao, P.S., et al. 1996. Fluid flow inhibits endothelial adhesiveness. Nitric oxide and transcriptional regulation of VCAM-1. Circulation. 94:1682-1689.

47. Marumo, T., et al. 1997. Platelet-derived growth factor-stimulated superoxide anion production modulates activation of transcription factor NF-кB and expression of monocyte chemoattractant protein 1 in human aortic smooth muscle cells. Circulation. 96:2361-2367.

48. Howard, A.B., et al. 1997. Cyclic strain induces an oxidative stress in endothelial cells. Am. J. Physiol. 272:C421-C427.

49. Hishikawa, K., and Luscher, T.F. 1997. Pulsatile stretch stimulates superoxide production in human aortic endothelial cells. Circulation. 96:3610-3616.

50. Hishikawa, K., et al. 1997. Pulsatile stretch stimulates superoxide production and activates nuclear factor- $\mathrm{KB}$ in human coronary smooth muscle. Circ. Res. 81:797-803.

51. Griendling, K.K., et al. 1994. Angiotensin II stimulates NADH and NADPH oxidase activity in cultured vascular smooth muscle cells. Circ. Res. 74:1141-1148.

52. Bardy, N., et al. 1996. Pressure and angiotensin II synergistically induce aortic fibronectin expression in organ culture model of rabbit aorta. Evidence for a pressure-induced tissue renin-angiotensin system. Circ. Res. 79:70-78.

53. Schiffrin, E.L., Thome, F.S., and Genest, J. 1983. Vascular angiotensin II receptors in renal and DOCA-salt hypertensive rats. Hypertension. 5:V16-V21.

54. Ogawa, T., et al. 1998. Regulation of aortic atrial natriuretic factor and angiotensinogen in experimental hypertension. J. Cardiovasc. Pharmacol. 32:1001-1008

55. Li, J.M., et al. 2002. Essential role of the NADPH oxidase subunit p47(phox) in endothelial cell superoxide production in response to phorbol ester and tumor necrosis factor- $\alpha$. Circ. Res. 90:143-150.

56. Burke, T.M., and Wolin, M.S. 1987. Hydrogen peroxide elicits pulmonary arterial relaxation and guanylate cyclase activation. Am. J. Physiol. 252:H721-H732.

57. Matoba, T., et al. 2000. Hydrogen peroxide is an endothelium-derived hyperpolarizing factor in mice. J. Clin. Invest. 106:1521-1530.

58. Griendling, K.K., and Harrison, D.G. 1999. Dual role of reactive oxygen species in vascular growth. Circ. Res. 85:562-563.

59. Zafari, A.M., et al. 1998. Role of NADH/NADPH oxidase-derived $\mathrm{H}_{2} \mathrm{O}_{2}$ in angiotensin II-induced vascular hypertrophy. Hypertension. 32:488-495.

60. Ushio-Fukai, M., et al. 1996. p22phox is a critical component of the superoxide-generating NADH/NADPH oxidase system and regulates angiotensin II-induced hypertrophy in vascular smooth muscle cells. J. Biol. Chem. 271:23317-23321.

61. Huang, M., et al. 1992. Development of hypertension in animals with reduced total peripheral resistance. Hypertension. 20:828-833.

62. Heller, R., et al. 2001. L-ascorbic acid potentiates endothelial nitric oxide synthesis via a chemical stabilization of tetrahydrobiopterin. J. Biol. Chem. 276:40-47.

63. Duffy, S.J., et al. 1999. Treatment of hypertension with ascorbic acid. Lancet. 354:2048-2049. 